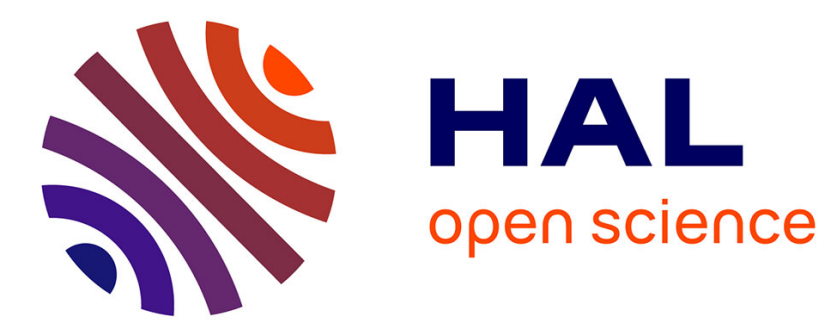

\title{
SMART 2008: Overview, synthesis and lessons learned from the International Benchmark
}

Benjamin Richard, Paolo Martinelli, François Voldoire, Thierry Chaudat, Salim Abouri, Nicolas Bonfils

\section{- To cite this version:}

Benjamin Richard, Paolo Martinelli, François Voldoire, Thierry Chaudat, Salim Abouri, et al.. SMART 2008: Overview, synthesis and lessons learned from the International Benchmark. Engineering Structures, 2016, 106, pp.166 - 178. 10.1016/j.engstruct.2015.10.029 . hal-01634201

\section{HAL Id: hal-01634201 \\ https://hal.science/hal-01634201}

Submitted on 2 Dec 2019

HAL is a multi-disciplinary open access archive for the deposit and dissemination of scientific research documents, whether they are published or not. The documents may come from teaching and research institutions in France or abroad, or from public or private research centers.
L'archive ouverte pluridisciplinaire HAL, est destinée au dépôt et à la diffusion de documents scientifiques de niveau recherche, publiés ou non, émanant des établissements d'enseignement et de recherche français ou étrangers, des laboratoires publics ou privés. 


\title{
SMART 2008: Overview, synthesis and lessons learned from the International Benchmark
}

\author{
Benjamin Richard $^{\mathrm{a}, *}$, Paolo Martinelli ${ }^{\mathrm{a}, \mathrm{d}}$, François Voldoire ${ }^{\mathrm{b}}$, Thierry Chaudat $^{\mathrm{a}}$, Salim Abouri ${ }^{\mathrm{c}}$, \\ Nicolas Bonfils ${ }^{c}$ \\ ${ }^{a}$ CEA, DEN, DANS, DM2S, SEMT, Laboratoire d'Etude de Mécanique Sismique, F-91191 Gif-sur-Yvette, France \\ ${ }^{\mathrm{b}}$ EDF, DRED, Acoustics and Mechanical Analysis Department, 1 avenue du Général de Gaulle, F-92141 Clamart, France \\ ${ }^{\mathrm{c}}$ EDF, SEPTEN, Dynamic and Earthquake Engineering Group, 12-14 avenue Dutriévoz, F-69628 Villeurbanne, France \\ d Politecnico di Milano, Department of Civil and Environmental Engineering, Piazza L. da Vinci 32, 20133 Milan, Italy
}

This paper reports the main results and conclusions of an International Benchmark jointly organized within the framework of a wide research program launched by the French Atomic Energy and Sustainable Energies Commission (CEA), Electricité De France (EDF) entitled "Seismic design and bestestimate Methods Assessment for Reinforced concrete buildings subjected to Torsion and nonlinear effect (SMART)". This research program included first an experimental campaign on reduced scaled specimen and shaking table tests, and second, a Benchmark exercise based on the contest of numerical methods and methodologies referring to the experimental results from the tests. The objectives of the Benchmark exercise were to compare the results obtained by conventional seismic assessment methods with those obtained by best-estimate methods, to compare the methodologies of taking into account uncertainties in the numerical analyses when a probabilistic assessment should be performed and to create an event allowing the international community in earthquake engineering to discuss the aforementioned topics of common interest. According to the analysis of the results, it turned out that (a) conventional methods are clearly able to provide relevant seismic assessment at the design level; (b) when dealing with overdesign seismic loadings, advanced best-estimate methods seem to be able to capture several key indicators such as the frequency shift of the peak of the response spectra; and (c) the blind nonlinear computations demonstrate a high robustness level of the specimen based on both structural and local damage indicators (frequency shift and inter-story drift, respectively).

\section{Introduction}

\subsection{Background}

Earthquakes are a major concern when dealing either with the design of new buildings or the periodic reassessment of existing ones. The seismic risk is carefully taken into account by structural engineers, especially when considering buildings requiring a highsafety level, such as those in the petro-chemical industry or electro-nuclear energy production, in a context of strengthening of seismic risk requirements. Recent international regulatory standards recommend designing reinforced concrete (RC) buildings devoted to nuclear activities as the assembly of shear walls and frames. Indeed, the assembly of such structural components offers

\footnotetext{
* Corresponding author.

E-mail address: Benjamin.Richard@cea.fr (B. Richard).

1 Current affiliation.
}

significant advantages over structures purely based on frames or shear walls. The story-drifts can be controlled in lower levels of the structure due to the stiff nature of RC walls. On the contrary, the frames increase the dissipative capability of the whole building, which leads to an increase in the displacement response of the structure. When this type of structure is regular or even slightly irregular, a consensus on the confidence level related to the assessment methodologies is nowadays accepted in the international community. However, the case of highly irregular frame-wall structures needs to be investigated, especially in the nonlinear behavior range. Indeed, geometric irregularities may lead to three-dimensional effects, such as torsion coupled with bending, especially when the structure exhibits a non-negligible eccentricity between the torsion center and the mass center.

To assess the safety and the robustness of such complex RC structures and related equipment regarding the seismic risk, it is necessary (i) to quantify the seismic margins, (ii) to quantify with an acceptable confidence level the floor response spectra (FRS) and 
Table 1

Participating teams.

\begin{tabular}{|c|c|c|c|c|c|c|}
\hline \multirow[t]{2}{*}{ Institution } & \multirow[t]{2}{*}{ Team number } & \multirow[t]{2}{*}{ Country } & \multicolumn{4}{|c|}{ Stage } \\
\hline & & & 1.A & 1.B & 2.A & 2.B \\
\hline French Atomic Energy and Sustainable Energies Commission (CEA) & 1 & France & $\mathrm{X}$ & $\mathrm{X}$ & & \\
\hline Public works special school (ESTP Paris) & 2 & France & $\mathrm{X}$ & & & \\
\hline Liège University & 3 & Belgium & $\mathrm{X}$ & & & \\
\hline National Institute of Applied Sciences & 4 & France & $\mathrm{X}$ & & & \\
\hline Iasi University & 5 & Romania & $\mathrm{X}$ & & & \\
\hline Shimizu Corporation & 6 & Japan & $\mathrm{X}$ & $\mathrm{X}$ & & \\
\hline AREVA Nuclear Production (AREVA-NP) & 7 & Germany & $\mathrm{X}$ & & $\mathrm{X}$ & $\mathrm{X}$ \\
\hline SCANSCOT & 8 & Sweden & $\mathrm{X}$ & $\mathrm{X}$ & $\mathrm{X}$ & $\mathrm{X}$ \\
\hline TRACTEBEL Engineering & 9 & Belgium & $\mathrm{X}$ & & & \\
\hline 3SR Laboratory/Joint research center (3SR-JRC) & 10 & France/Italy & $\mathrm{X}$ & $\mathrm{X}$ & & \\
\hline Japan Nuclear Energy Safety Organization (JNES) & 11 & Japan & $\mathrm{X}$ & $\mathrm{X}$ & $\mathrm{X}$ & $\mathrm{X}$ \\
\hline Brookhaven National Laboratory & 12 & USA & $\mathrm{X}$ & $\mathrm{X}$ & $\mathrm{X}$ & $\mathrm{X}$ \\
\hline Korea Atomic Energy Research Institute & 13 & Republic of Korea & $\mathrm{X}$ & $\mathrm{X}$ & & \\
\hline Onsala Ingenjörsbyră & 14 & Sweden & $\mathrm{X}$ & & & \\
\hline CKTI-Vibroseism & 15 & Russia & $\mathrm{X}$ & $\mathrm{X}$ & $\mathrm{X}$ & $\mathrm{X}$ \\
\hline Fortum Nuclear Services Ltd & 16 & Finland & $\mathrm{X}$ & $\mathrm{X}$ & $\mathrm{X}$ & $\mathrm{X}$ \\
\hline GRAITEC SA & 17 & France & $\mathrm{X}$ & & & \\
\hline IDOM & 18 & Spain & $\mathrm{X}$ & & & \\
\hline IOSIS Industries - SECHAUD ET METZ & 19 & France & $\mathrm{X}$ & $\mathrm{X}$ & & \\
\hline Politecnico di Milano & 20 & Italy & $\mathrm{X}$ & & & \\
\hline Electricité de France (EDF) & 21 & France & $\mathrm{X}$ & $\mathrm{X}$ & $\mathrm{X}$ & $\mathrm{X}$ \\
\hline Numerical Engineering and Consulting Services (NECS) & 22 & France & $\mathrm{X}$ & $\mathrm{X}$ & & \\
\hline Pakistan Atomic Energy Commission & 23 & Pakistan & $\mathrm{X}$ & $\mathrm{X}$ & $\mathrm{X}$ & $\mathrm{X}$ \\
\hline Atomic Energy of Canada Ltd (AECL) & 24 & Canada & $\mathrm{X}$ & $\mathrm{X}$ & $\mathrm{X}$ & $\mathrm{X}$ \\
\hline Basler und Hofmann Ingenieure und Planer AG & 25 & Switzerland & $\mathrm{X}$ & $\mathrm{X}$ & $\mathrm{X}$ & $\mathrm{X}$ \\
\hline ROBOBAT & 26 & France & $\mathrm{X}$ & & & \\
\hline LMT/ENS Cachan & 27 & France & $\mathrm{X}$ & $\mathrm{X}$ & & \\
\hline Risk Engineering Ltd & 28 & Bulgaria & $\mathrm{X}$ & $\mathrm{X}$ & & \\
\hline Korea Institute of Nuclear Safety & 29 & Republic of Korea & $\mathrm{X}$ & & & \\
\hline Middle East Technical University (METU) & 30 & Turkey & $\mathrm{X}$ & $\mathrm{X}$ & & \\
\hline Nuclear and Radiation Safety Center of ANRA & 31 & Armenia & $\mathrm{X}$ & & & \\
\hline Institute for Radioprotection and nuclear safety (IRSN) & 32 & France & $\mathrm{X}$ & $\mathrm{X}$ & & \\
\hline ALTAIR Engineering AB & 33 & Sweden & & $\mathrm{X}$ & $\mathrm{X}$ & $\mathrm{X}$ \\
\hline Stangenberg und Partner & 34 & Germany & & $X$ & $X$ & $X$ \\
\hline
\end{tabular}

(iii) to take into account uncertainties related to the input ground motions and the input material parameters that feed structural models. As usual, engineering practices can be gathered in two different families: (i) the conventional analyses and (ii) the bestestimate methods. To quantify in a meaningful way the seismic margins, conventional analyses that are usually simple and conservative are not sufficient. Best-estimate methods with advanced nonlinear constitutive laws are required to carry out in an efficient way the seismic assessment of such structures. Furthermore, the relevancy of advanced nonlinear models is not only related to the material parameters to be considered, but also to the variability of the input ground motion used to realize the structural assessment. Indeed, either material parameters or input ground motions are subjected to uncertainties that should be taken into account From the aforementioned discussion, it is clear that improvements in the fields of nonlinear and uncertainties modeling are of primary importance for the earthquake engineering community.

The past decades were marked by major events that gathered the earthquake engineering community along the same path of the improvement of knowledge in the field of structural dynamics of low span shear walls and related assessment methodologies. The former Nuclear Power Engineering Corporation of Japan (NUPEC) organized a similar event, under the auspices of the Nuclear Energy Agency (NEA) Organization of Economic Cooperation and Development (OECD), twenty years ago. The RC structure was regular and U-shaped with low span shear walls. The main conclusions were that advanced nonlinear dynamic methods still have to be improved, in particular, when dealing with overdesign seismic ground motion leading to the structure working close to its ultimate limit state [1-5]. Some years later, within the framework of the CAMUS research program carried out at the French Atomic
Energy and Sustainable Energies Commission (CEA) between 1996 and 2002 on a symmetric, in-plane, five-story RC wall $1 / 3$ th scaled mock-up [6,7], shaking table tests were carried out to better assess the dynamic behavior of RC structures [8]. In addition, the predictive capabilities of existing assessment methodologies were evaluated due to two international benchmarks held in 1998 and 2003. It appears that the seismic margins were frequency dependent; this conclusion was confirmed by the related numerical experiences. In 2006, a blind prediction contest on the seismic response of a seven-story full-scale RC building with cantilever structural walls acting as the lateral force resisting system was launched by the Network for Earthquake Engineering Simulation (NEES), Portland Cement Association and University of California at San Diego. The objective of that research program was to verify the seismic response of RC wall systems designed for lateral forces obtained from a displacement-based design methodology, with particular emphasis placed on the interaction between the walls, slabs and gravity system, and on the issues related to construction optimization [9-14].

To move forward and to bring new knowledge when dealing with the seismic assessment methodologies of RC structures being highly irregular, the Seismic design and best-estimate Methods Assessment for Reinforced concrete building subjected to Torsion and nonlinear effect (SMART 2008) research project joining the CEA, Electricité de France (EDF) and partially supported by the International Atomic Energy Agency (IAEA) was launched in 2006. Within this framework, the International Benchmark, SMART 2008 , was organized to reach the aforementioned objectives. A representative of a typical, simplified, half-part of an electrical nuclear building 1/4th scaled mock-up was designed, built and tested between June and October 2008 on an AZALEE shaking table, 
at the Seismic Mechanics Studies (EMSI) laboratory [15,16]. It was composed of three walls with openings forming a $U$ shape and three stories. The specimen was designed according to the French current nuclear engineering practice [16]. Design spectra correspond to the seismic loading of a low to medium seismic area, anchored at PGA equal to $0.2 \mathrm{~g}$. Seismic inputs of increasing intensity (up to a maximum PGA of $0.9 \mathrm{~g}$ ) were applied to the mock-up; these synthetic accelerograms were generated from the design spectrum.

\subsection{SMART 2008 International Benchmark content}

The SMART 2008 International Benchmark was organized between 2008 and 2010; thirty-four participating teams were registered. A list of participants is provided in Table 1 including in which parts of the benchmark they were involved.

The SMART 2008 International Benchmark consisted of two major stages, namely stage 1 and stage 2 , and two scientific workshops. The participants' results remained anonymous. The objectives of the benchmark were (i) to share with the international community the current engineering practices to perform seismic assessments (in particular, to evaluate conventional design methods for structural dynamic responses and FRS calculations, and to compare best-estimate methods for structural dynamic responses and FRS evaluations) and (ii) to promote the use of probabilistic methodologies addressing random and epistemic uncertainties, quantifying vulnerability associated to variabilities. The intent was to assess design practices and improve engineering knowledge concerning the seismic response of RC structures subjected to low and far-beyond design seismic motions, and to share experience and improve probabilistic approaches in order to provide the engineering community with more efficient tools and guidelines. To reach these objectives, an extensive experimental campaign on an RC mock-up that was designed to exhibit torsional and nonlinear effects was carried out, and the measurements fed the benchmark $[15,16]$. It is important to notice the lack of experimental materials in the published literature for such complex structures; the ambition of the SMART 2008 research joint project was to bring about new knowledge, not only on the experimental aspect, but also on the applicability of existing seismic assessment methods to improve engineering practices.

Stage 1 was split into two sub-stages, namely stage 1.A and stage 1.B. Stage 1.A was devoted to the comparison of conventional approaches and best-estimate methods under blind conditions, since no experimental results (only design data) were provided to the participants by the local organizing committee. Stage 1.B gave participants the opportunity to adjust, or, in some cases, to modify, their numerical models based on the measurements realized during the low-intensity seismic test (linear range). In particular, the full set of experimental data, including inputs and outputs related to the design input ground motion (PGA equal to $0.2 \mathrm{~g}$ ), was provided to the participants to allow them to improve their model calibration. In addition, the participants were asked to use their updated numerical model to assess the dynamic behavior of the $\mathrm{RC}$ mock-up when subjected to an overdesign input ground motion (PGA equal to $0.4 \mathrm{~g}$ ). For both parts of stage 1 , both kinematic (displacements and accelerations) and static quantities (internal stress resultants and moments) were required. Stage 2 was also split into two sub-stages, namely stage 2.A and stage 2.B. The most sensitive input parameters, including the seismic loading, were identified, and the probabilistic assessment of the vulnerability of the RC mock-up was conducted. Then, in stage 2 .A, the sensitivity analysis was carried out. In stage $2 . B$, the participants computed the so-called fragility curves by using the methodology of their choice to estimate under several failure criteria the median capacity and the log-standard deviation. In this paper, stage 2 is not presented. The use of probabilistic methodologies addressing random and epistemic uncertainties will be discussed in future work.

\subsection{Outlines}

This paper is devoted to presenting an overview of the work carried out within the framework of the SMART 2008 International Benchmark. In addition, a synthetic presentation of the main results is made before lessons and remarks are drawn for further works. To reach the aforementioned objectives, this paper is outlined as follows. In the first part, an overview of the participants' work is given, and synthetic descriptions of the output results are presented. In a second part, the data are analyzed in two directions. On one hand, the existence of seismic margins is discussed in the case of an RC structure subjected to torsion and nonlinear effects designed with current engineering practices and applicable standards in the nuclear energy field. On the other hand, the capability of nonlinear constitutive models used in best-estimate methods to assess the seismic behavior of such a complex RC structure is also discussed.

\section{Stage 1.A: blind computations}

\subsection{Assumptions, model descriptions and assessment methods}

The work requested of the participants in stage 1.A was carried out under a blind condition, not only from the point of view of the seismic inputs, but also for the seismic outputs. The participants had to perform four tasks: (i) a static analysis under self-weight, (ii) a modal analysis, (iii) a basic design conventional method to define the conservative response spectrum and (iv) a bestestimate method to make a seismic assessment of the RC mockup at the design and overdesign levels. In addition, a description of each numerical model was required in order to clarify the assumptions made, mainly in terms of model complexity, seismic assessment methodology used and damping value retained. To perform the aforementioned analyses, each participating team had access to the same information: the drawings of the mockup, including formwork and steel reinforcement ones, the design elastic material properties related to the concrete and steel, a description (location and value) of the additional masses and the targeted seismic input represented by the response spectrum at the ground level. Various types of finite element models were developed by the participants. An overview is given in Fig. $1 \mathrm{a}$ and $1 \mathrm{~b}$ for conventional and best-estimate analyses, respectively. Most of the participants used a mixed model, including shell finite elements for shear walls and slabs, fiber beam finite elements for the column and solid finite elements for the foundation. Furthermore, one can notice that the participants used almost the same models for both types of analyses. The numerical models were considered clamped at the lowest face of the foundation, and none of the participants modeled the shaking table at this stage.

An overview of the assessment methods used is presented in Fig. 2a and $\mathrm{b}$ for conventional and best-estimate analyses, respectively. In addition, none of the participants used a push-over based analysis as a conventional method. Indeed, mainly modal spectral and time history, either linear or nonlinear, analyses were considered. One can notice that, even for the conventional analysis, time history analyses were used. Obviously, time history analyses were used as a best-estimate method. Since the damping ratio is a key parameter that highly influences the output results, it was interesting to observe the various values considered with respect to the type of assessment methodology used by the participants. As far 


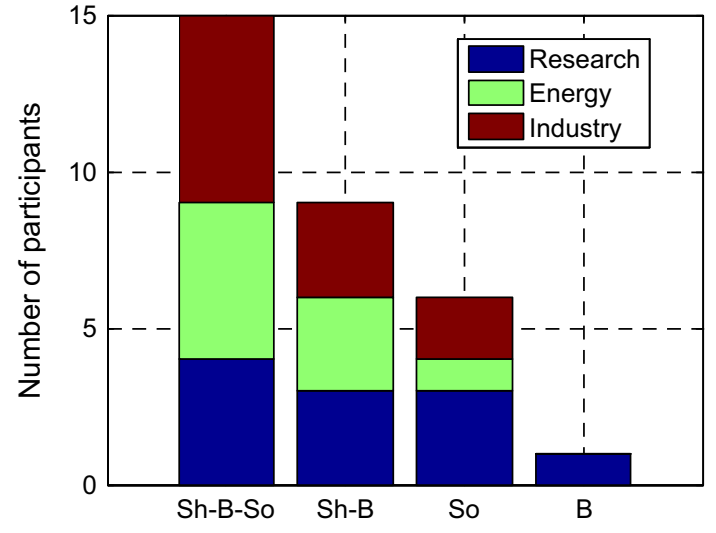

(a) Conventional analyses.

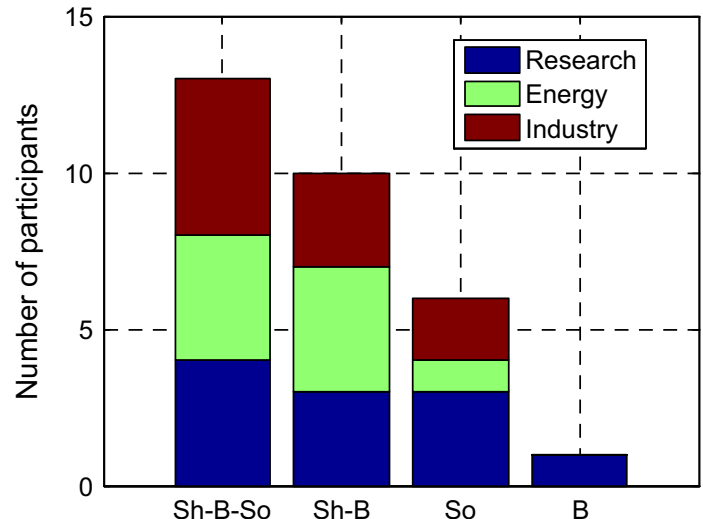

(b) Best-estimate analyses.

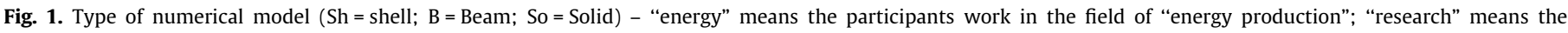
participants work in academic institutions; "industry" means the participants work in design offices not necessarily related to the field of energy production.

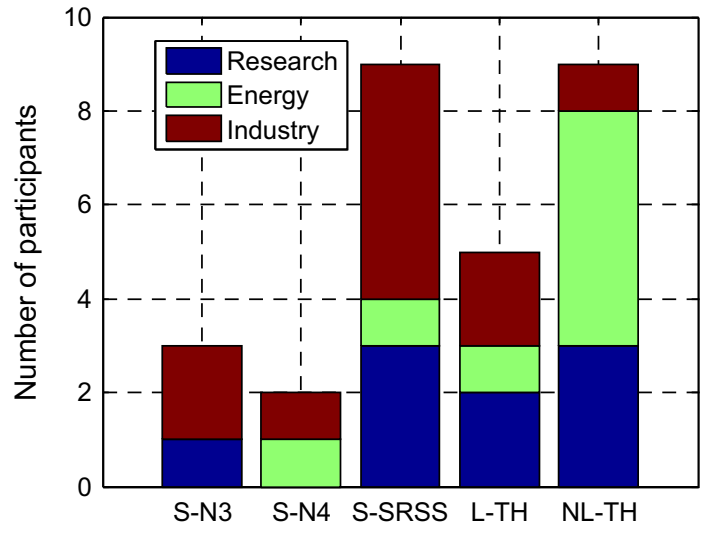

(a) Conventional analyses.

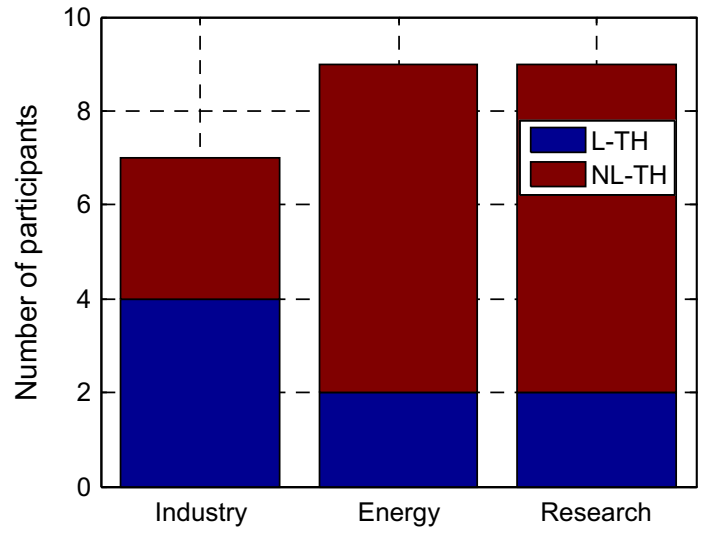

(b) Best-estimate analyses.

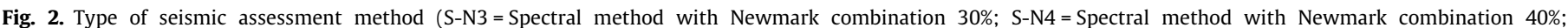

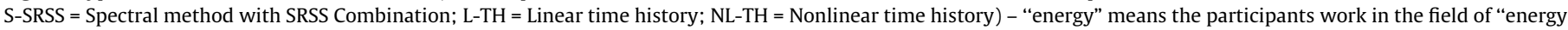

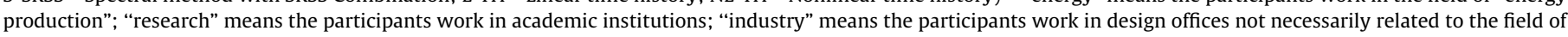
energy production.

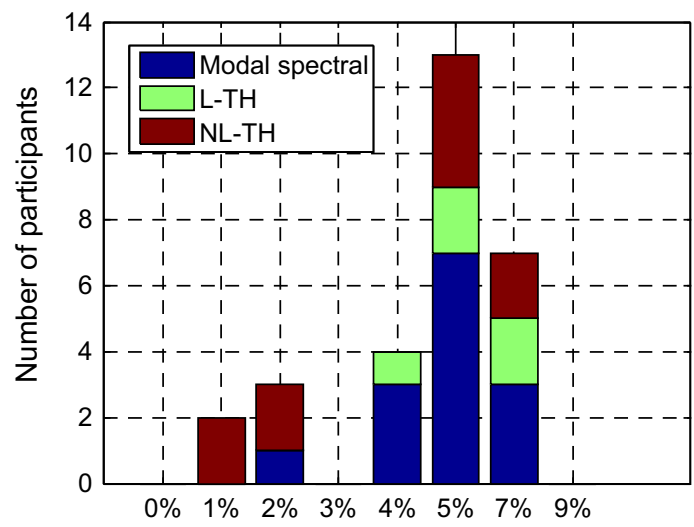

(a) Conventional analyses.

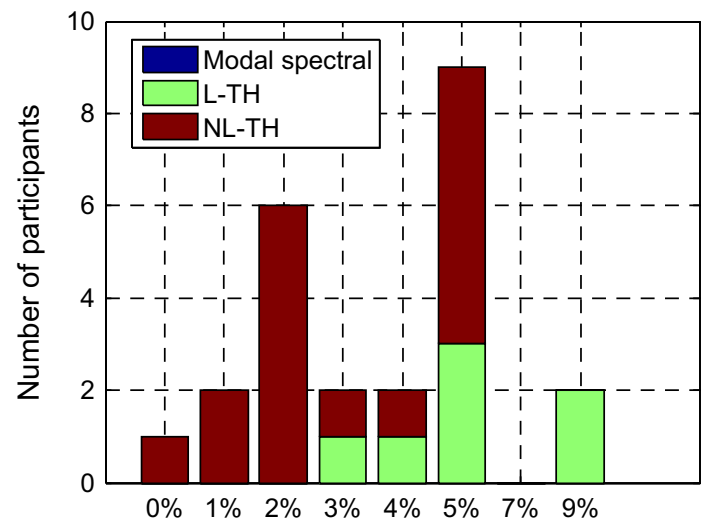

(b) Best-estimate analyses.

Fig. 3. Damping ratio used according to the type of assessment method (L-TH = Linear time history; NL-TH = Nonlinear time history).

as modal spectral analyses were concerned, modal damping was considered. The damping ratio was assumed to be equal for all the modes. Rayleigh's damping was used in the case of the time history analyses. The overview is shown in Fig. 3a and b for conventional and best-estimate analyses, respectively. There was an overall shift in the damping ratio from $5 \%$ in the case of conventional analyses to $2 \%$ in the case of best-estimate analyses. In particular, a damping ratio equal to $2 \%$ was only considered when 
nonlinear time history analyses were carried out, which was in accordance with the current engineering practices and regulations.

From the presentation of the models, the assumptions and the assessment method chosen by the participants, one can observe that the current seismic engineering practice was represented in a satisfactory way by the participant pool.

\subsection{Model calibration, conventional assessment and best-estimate assessment of the design input ground motion}

In order to assess the calibration of the numerical models, the empirical cumulative distribution function (ECDF) of the masses and the first eigenfrequencies of the participant pool are presented in Fig. 4a and b, respectively. The mass of the unloaded RC mockup was indexed 1 and the mass of the loaded (with additional masses) RC mock-up was indexed 2; their respective experimental values were $10.44 \mathrm{t}$ and $44.29 \mathrm{t}$. The masses were computed from the structural response under self-weight. The experimental masses were described in a satisfactory way. The results from the preliminary modal analysis are shown in Fig. 4b. Nevertheless, we report patent errors in the mass assignment of some participants' models, leading to the disregard of their results in the sequel. All participants considered the RC mock-up as loaded with additional masses and fixed at the lowest face of the foundation. It was interesting to observe that none of the participants used a specific model to take into account the shaking table. First, for the first three eigenfrequencies, a similar trend appeared. Indeed, the experimental eigenfrequencies were overestimated and, as expected, the gap between the measurements and the computed values increased with the order of the considered mode. Since the masses were represented in a satisfactory way, as shown in Fig. 4a, one could conclude that the numerical models were too stiff. This specific boundary condition did not seem to be equivalent to a perfect fixed base condition since some flexibility might come from the upper plate of the shaking table or from some shaking table/mock-up interaction [17]. Second, the ECDFs shown in Fig. 4b are vertical-shaped, which highlighted the low scattering of the first eigenfrequencies. This could be explained by the fact that all the participants considered the mock-up fixed at the lower face of the foundation, since boundary conditions are generally responsible for the main part of the scattering when dealing with initial modal properties.

Another point of interest is to compare the results of conventional assessment methods with best-estimate ones when the seismic design level is considered. Due to the huge amount of available results provided by the participants, only the ones related to the most excited point, namely point $\mathrm{D}$ [16], were shown for each horizontal direction and for the first and third floors. The results expressed in terms of acceleration response spectra computed for 5\% damping are presented in Figs. 5-8. For each couple (direction, floor), the mean, the median and the 90\% confidence interval are presented. In Figs. 5 and 6, one can observe the results in the $X$ direction for the first and third floors, respectively. Despite the fact that the scattering was different, the median and the mean acceleration response spectra exhibited similar trends. The output results from conventional methods were consistent with those from best-estimate ones. In Figs. 7 and 8, which show the outputs results in the $Y$ direction for both first and third floors, the mean and the median acceleration response spectra computed by bestestimate methods had higher amplitudes for all the frequency ranges compared with those obtained by conventional methods. This observation was more obvious in the case of the third floor. This difference in terms of the dynamic response of the RC mockup in the $Y$ direction could be explained by its asymmetric design. In addition, this difference might also be explained by the fact that different assumptions to model damping were considered. It is shown in Fig. 3 that, in the case of conventional methods, damping ratios between $5 \%$ and $7 \%$ were mainly considered, as required in standards. Moreover, since spectral methods were used by the majority of participants, it was important to notice that a modal damping (constant per mode) was considered. On the contrary, in the case of best-estimate methods, damping ratios ranged between $2 \%$ and $5 \%$. Furthermore, as either linear or nonlinear time history analyses were mainly used, well-known Rayleigh's damping based models (frequency dependent) were used. Therefore, the damping ratio corresponded to a given frequency range that was selected by the participants. It seems that best-estimate models were less dissipative than those used for conventional analyses.

\subsection{Best-estimate assessment of overdesign seismic loadings}

In order to assess the capabilities of the best-estimate methods to predict the seismic response of the RC mock-up when dealing with overdesign input ground motions, the participants were asked to consider the whole seismic sequence. One can notice that all the seismic inputs were proportional. For each seismic input, the participants provided acceleration response spectra for $5 \%$ damping computed at the corners of each floor for both horizontal

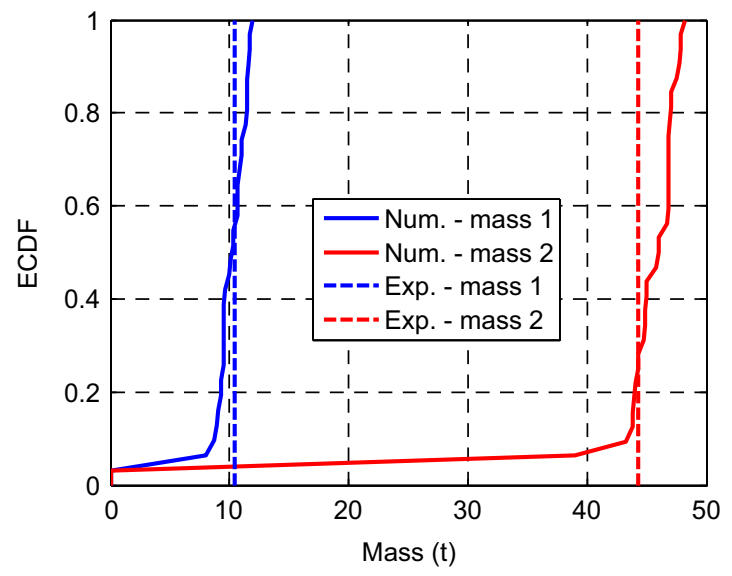

(a) Mass of the unloaded RC mock-up (mass 1) and of the loaded mock-up (mass 2)

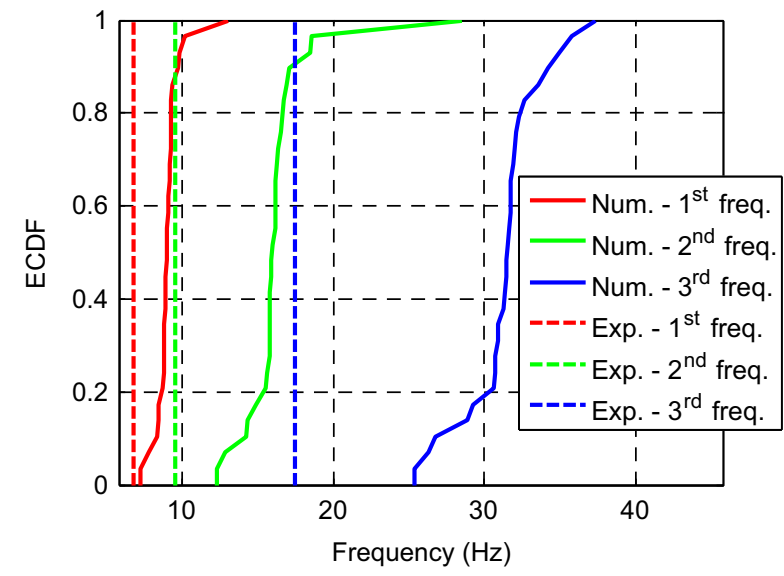

(b) First, second and third eigenfrequencies

Fig. 4. Empirical cumulative density function over the participants' pool. 


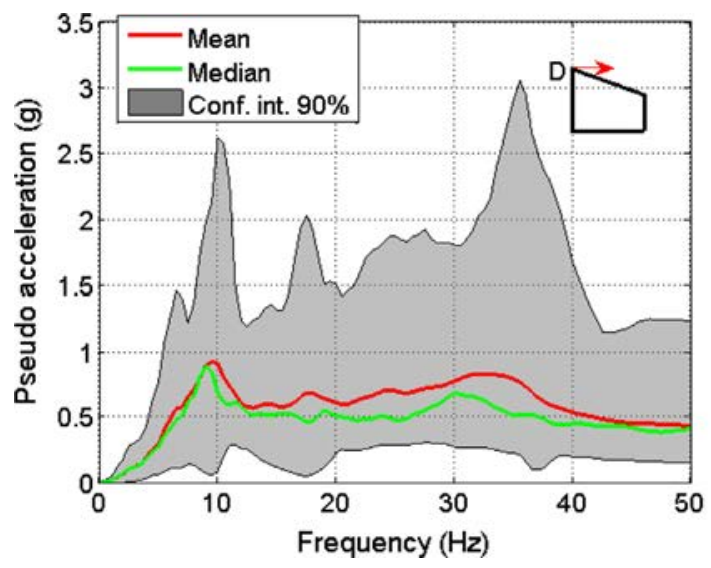

(a) Conventional methods

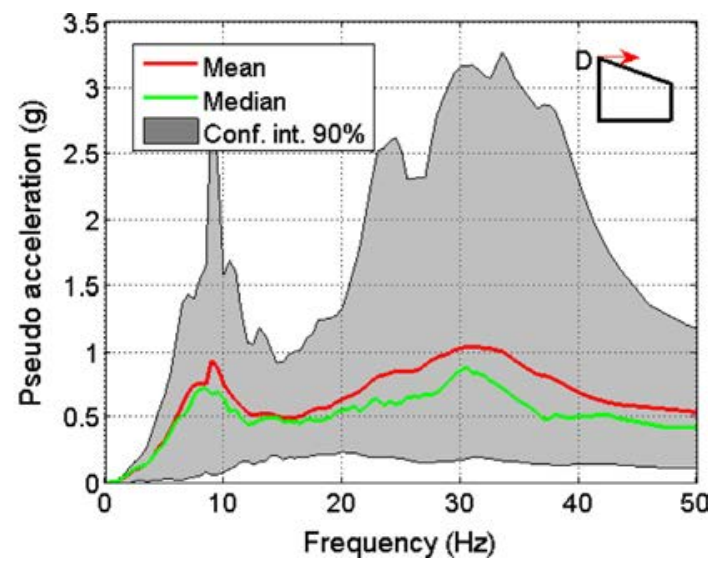

(b) Best-estimate assessment methods

Fig. 5. Statistical description of the response spectra computed at point $\mathrm{D}$ in $X$ direction at the 1 st floor for $5 \%$ damping.

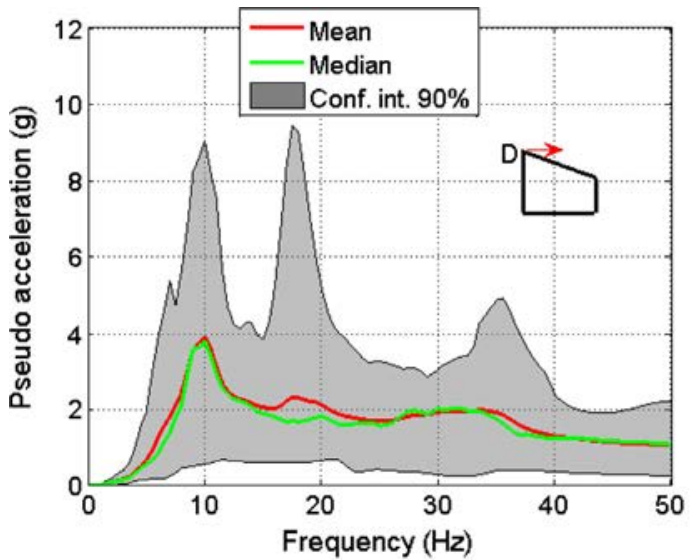

(a) Conventional methods

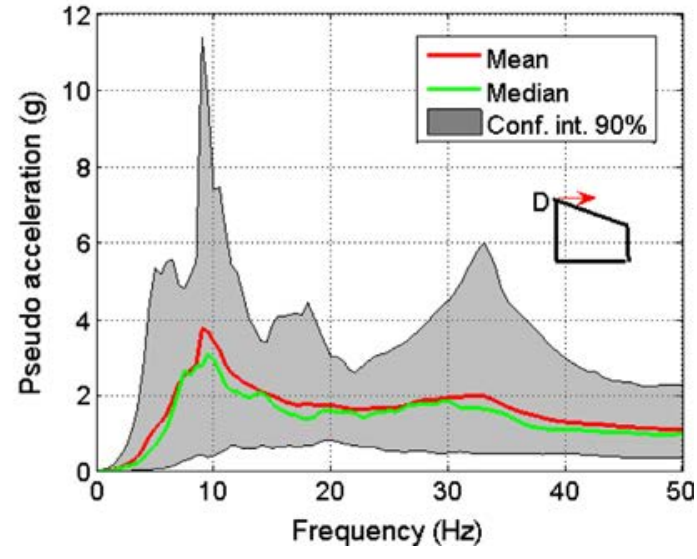

(b) Best-estimate assessment methods

Fig. 6. Statistical description of the response spectra computed at point D in $X$ direction at the 3rd floor for 5\% damping.

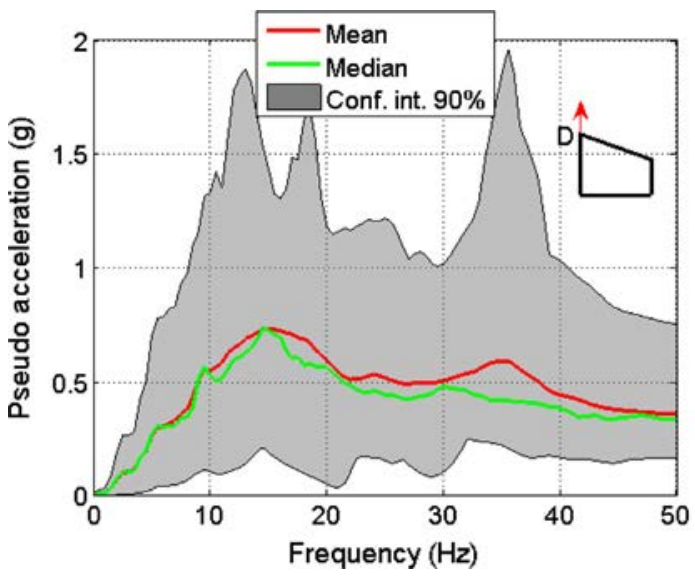

(a) Conventional methods

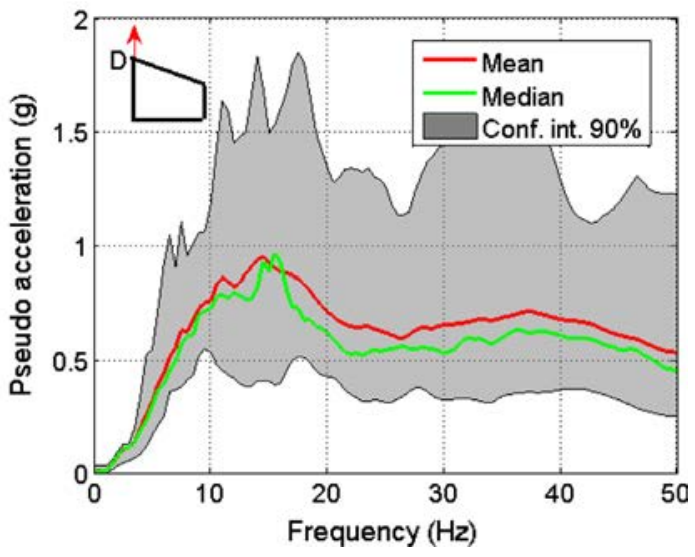

(b) Best-estimate assessment methods

Fig. 7. Statistical description of the response spectra computed at point D in $Y$ direction at the 1 st floor for $5 \%$ damping. 


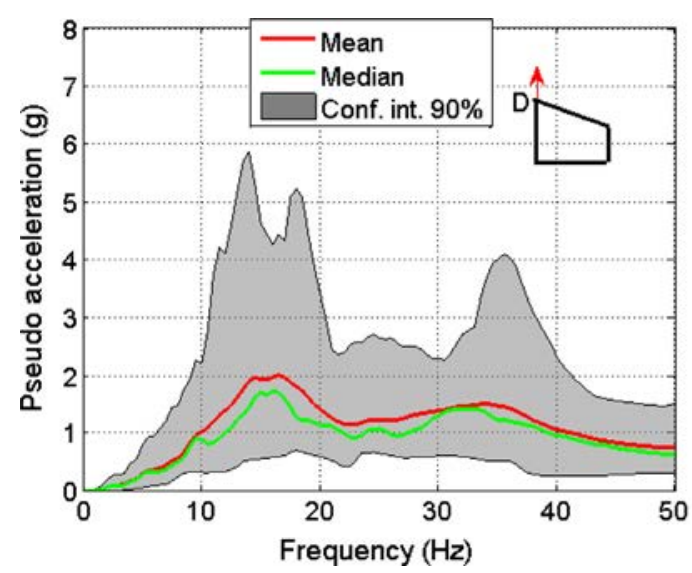

(a) Conventional methods

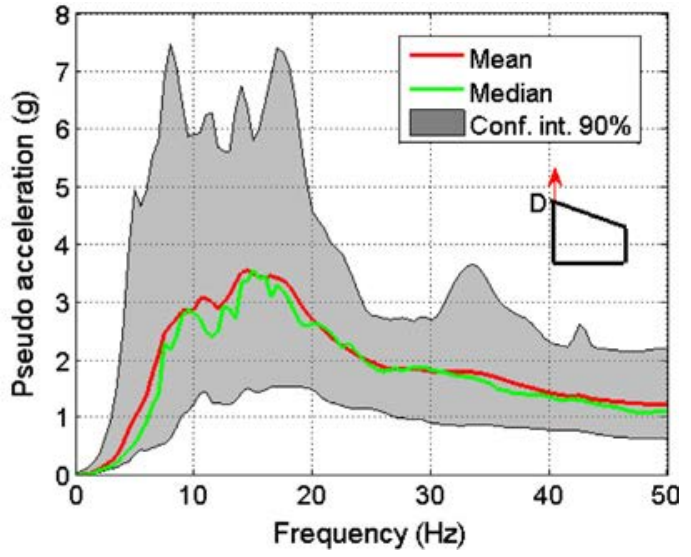

(b) Best-estimate assessment methods

Fig. 8. Statistical description of the response spectra computed at point D in $Y$ direction at the 3rd floor for $5 \%$ damping.

$X$ and $Y$ directions. The output results from the benchmark exercise were presented in terms of seismic margins and were compared with those coming from the experimental campaign [16]. Two failure criteria were considered and expressed in Eqs. (1) and (2) as follows:

$g_{\Delta X}^{k}\left(\Delta X^{k} ; \Delta X_{0}\right)=\max _{\tau \in[0, t]}\left\{\left|\Delta X^{k}(\tau)\right|\right\}-\Delta X_{0}$

$\left.g_{\Delta f}^{i}\left(f^{i} ; f_{R E F}^{i}, \mathrm{~s}_{0}\right)=100 \mathrm{x} \frac{f_{R E F}^{i}-f^{i}}{f_{R E F}^{i}}\right)-\mathrm{s}_{0}$

where $g_{\Delta X}^{k}$ stands for a failure criterion expressed in terms of maximum inter-story drift $\Delta X^{k}$ computed at point $k$ (the inter-story drift is here defined as the relative displacement between the stories $k$ and $k-1)$. The failure criterion $g_{\Delta f}^{i}$ is expressed in terms of the $i^{\text {th }}$ eigenfrequency shift, with $f_{R E F}^{i}$ the $i^{\text {th }}$ eigenfrequency of the undamaged structure and $f^{i}$, the $i^{\text {th }}$ eigenfrequency accounting for stiffness reduction by damage. $\Delta X_{0}$ and $\mathrm{s}_{0}$ are two thresholds that have to be chosen. Basically, engineering practices, expert judgments or design standards drive this choice. Failure occurs as soon as the failure functions become positive; in practice, it does not mean that the structure is collapsed, but, according to the engineering practices, that serviceability is questionable. The failure criteria $g_{\Delta X}^{k}$ and $g_{\Delta f}^{i}$ reflect the effects of local damage and of damage at the whole structure scale, respectively. The first is inspired by the usual criterion devoted to RC multistory moment-resisting frames [18], while the second seems more adapted to the equipment seismic analysis from floor spectra. The seismic margin $\mathrm{M}_{\mathrm{g}}$ can be defined as the lowest ratio $\lambda^{i}$ between the PGA of the considered input signal and the PGA of the design input signal for which the failure criterion is about to be overcome. The loading factor $\lambda^{i}$ is defined as follows:

$\lambda^{i}=\frac{P G A^{i}}{P G A^{\text {Design }}}$

where $P G A^{\text {Design }}$ stands for the PGA of the design seismic signal (equal to $0.2 \mathrm{~g}$ ), while $P G A^{i}$ is the PGA of the seismic input. According to this definition and considering a generic failure criterion $g$, $\mathrm{M}_{\mathrm{g}}$ can be expressed as follows:

$M_{g}=\operatorname{argmin}_{\lambda_{i}}\left\{\lambda_{i} \mid g>0\right\}$

It is important to notice that the seismic margin is clearly dependent on the type of failure criterion chosen. To quantify the seismic margins, the failure function $g_{\Delta X}^{k}$ has been evaluated at
Table 2

Prescribed values of the thresholds in the failure functions ( $h=$ story height).

\begin{tabular}{lll}
\hline $\begin{array}{l}\text { Damage } \\
\text { level }\end{array}$ & $\begin{array}{l}\text { Inter-story drift threshold } \Delta X_{0} \\
(\mathrm{~mm})\end{array}$ & $\begin{array}{l}\text { Eigenfrequency shift } \\
\text { threshold } s_{0}(\%)\end{array}$ \\
\hline Limited & $\frac{h}{400}$ & 15 \\
Controlled & $\frac{h}{200}$ & 30 \\
Extended & $\frac{h}{100}$ & 50 \\
\hline
\end{tabular}

points D, located at the second and the third floors, in both directions for the same reasons as those exposed in the previous section. Regarding the failure function $g_{\Delta f}^{i}$, the frequency shifts were computed by analyzing the modulus of the transfer function between the upper face of the foundation and the point $\mathrm{D}$ located on the third floor. Hence, the ith eigenfrequency $f^{i}$ is estimated by the frequency of the ith peak of the acceleration transfer function; it can also be obtained by solving the eigenvalue problem using the updated stiffness matrix of the damaged structure. For both failure functions $g_{\Delta X}^{k}$ and $g_{\Delta f}^{i}$, three thresholds $\Delta X_{0}$ and $s_{0}$ have been considered, allowing to define three conventional damage levels: limited, controlled and extended damage. Their values are presented in Table 2. In the following analysis, seismic margin estimations in connection with the failure criteria presented in Table 2 are carried out considering the mean values computed over the benchmark participants.

In Fig. 9, experimental and numerical absolute values of the maximum inter-story drift computed at point $\mathrm{D}$ in both $X$ and $Y$ directions versus several loading factors are shown. One can notice that the choice of the $X$ or $Y$ direction is of primary importance since the subsequent interpretations are strongly dependent on it. This observation reflects the asymmetric nature of the RC mock-up. Regarding the results presented in Fig. 9a (inter-story drift in $X$ direction), a seismic margin between 2 and 3 can be estimated if only limited damage is allowed. The failure criteria defining controlled damage and extended damage were never reached. If the seismic margins had been estimated, they would have been higher than 4 . One can also notice the non-negligible gap between experimental and numerical results, which was not fully surprising due to the local nature of the failure criterion considered. On the contrary, the results obtained in the $Y$ direction led to higher seismic margins, since even the failure criterion defining a limited damage was never reached even for a loading factor equal to 4 . This result clearly showed the ability of best-estimate methods to provide, under a blind condition, a fairly good estimation of the seismic margins for various damage levels allowed. 


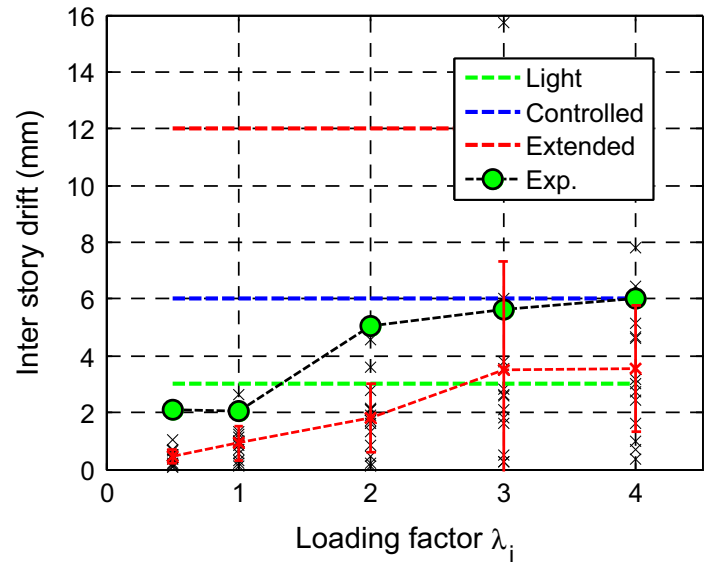

(a) Inter story-drift computed in the direction $\mathrm{X}$

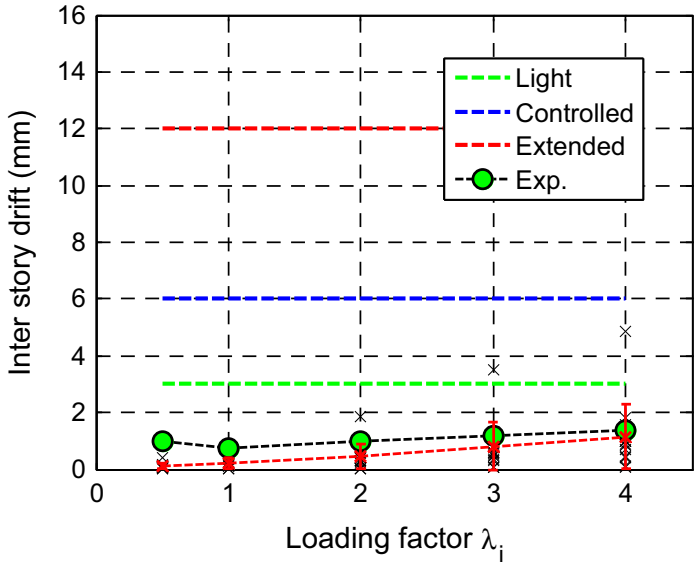

(b) Inter story-drift computed in the direction $\mathrm{Y}$

Fig. 9. Absolute values of the maximum inter-story drift computed at point $\mathrm{D}$ versus the loading factor.

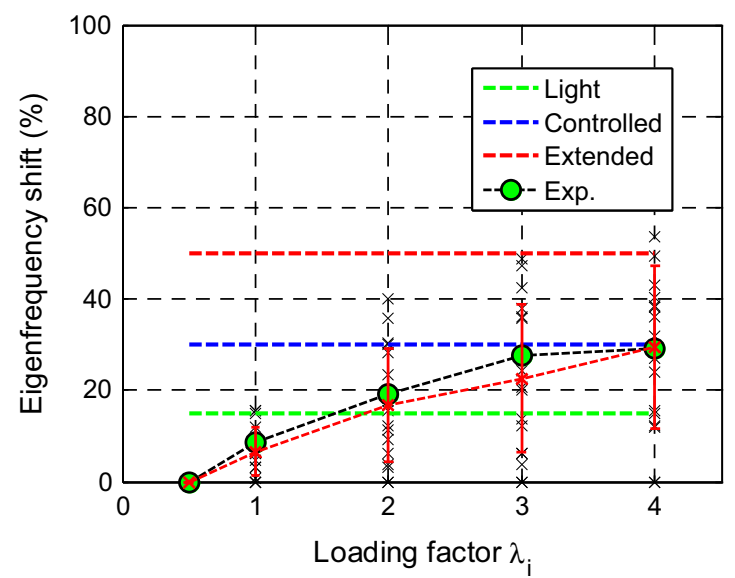

Fig. 10. Shift of the 1 st peak-frequency versus the loading factor.

In Fig. 10, the experimental and numerical 1st peak-frequency shift versus loading factors is shown. It is necessary to emphasize the fact that peak-frequencies were estimated by computing the acceleration transfer function modulus between the point $D$ at the third floor and the foundation, in the $X$ direction. The results shown in Fig. 10 lead to an estimation of the seismic margin between 1 and 2 if only limited damaged is allowed. If one considers the failure criterion for a controlled damage state, the seismic margin equal to 4 can be estimated. Last, in the case of extended damage, the seismic margin was higher than 4 , since the corresponding failure criterion was never reached in mean. The results mentioned in this discussion are summarized in Table 3. It was interesting to notice that the estimation of the seismic margins was not objective with respect to the type of failure criteria that

Table 3

Estimated seismic margins for various failure criteria.

\begin{tabular}{clcll}
\hline Failure criterion & & $\begin{array}{l}\text { Limited } \\
\text { damage }\end{array}$ & $\begin{array}{l}\text { Controlled } \\
\text { damage }\end{array}$ & $\begin{array}{l}\text { Extended } \\
\text { damage }\end{array}$ \\
\hline Inter-story drift & $X$ direction & 3 & $>4$ & $>4$ \\
& $Y$ direction & $>4$ & $>4$ & $>4$ \\
Peak-frequency & 1st & 2 & 4 & $>4$ \\
$\quad$ shift & eigenfrequency & & & \\
\hline
\end{tabular}

Table 4

Inputs and outputs in stage 1.B.

\begin{tabular}{llll}
\hline $\begin{array}{l}\text { Run } \\
\text { number }\end{array}$ & $\begin{array}{l}\text { PGA } \\
(\mathrm{g})\end{array}$ & Input data & Output data \\
\hline 4 & 0.2 & $\begin{array}{l}\text { Provided to the } \\
\text { participants } \\
\text { Provided to the } \\
\text { participants }\end{array}$ & $\begin{array}{l}\text { Provided to the } \\
\text { participants } \\
\text { Asked to the participants }\end{array}$ \\
\hline 8 & 0.4 & \\
\hline
\end{tabular}

were considered. When dealing with a criterion expressed in terms of inter-story drifts, the seismic margins appeared to be higher than in the case of a criterion expressed in terms of peakfrequency shift, which could be understood by recalling that the aims of the two proposed criteria were not identical. As mentioned previously, this could be explained by the local nature of the criterion expressed in terms of inter-story drift compared with the one expressed in terms of peak-frequency shift that accounted for the overall damage at the structural scale.

Experimental/numerical comparisons that were shown in this section allow for concluding that nonlinear approaches used as a best-estimate assessment method for a complex nuclear building designed according to the current French engineering practices were able to quantify in a satisfactory way the seismic margins for various failure criteria. In addition, the results demonstrated the structural robustness of the RC specimen under study.

\section{Stage 1.B: post-test computations}

\subsection{Main content}

Stage 1.B aimed to assess the capability of the numerical models to describe the dynamic response of the RC mock-up for a seismic ground motion where the level was higher than the design level. Since the predictive capability of a numerical model is strongly dependent on the input parameters chosen, specific attention was paid to provide the necessary data set to ensure a satisfactory calibration to the benchmark participants. The experimental measurements (inputs and outputs) acquired during the design level (PGA equal to $0.2 \mathrm{~g}$ ) were provided to the participants. Based on those data, the participants had the opportunity to calibrate their numerical models in the quasi-linear range. Then, the predictive capability of the numerical models was evaluated based on an 
overdesign seismic run (PGA equal to $0.4 \mathrm{~g}$ ) for which only the experimental measurements acquired on the shaking table plate were provided to the participants. Considering these data sets for the design run and for an overdesign run, the participants were asked to provide the acceleration time histories and relative displacements for both $X$ and $Y$ directions (the reference being the bottom of the foundation) at points A, B, C and D located at the 3rd floor. The data provided and required from the participants are summarized in Table 4.

\subsection{Low-intensity seismic ground motion: design level $-P G A=0.2 \mathrm{~g}$}

In this section, the numerical results provided by the participants for the design run are shown. The FRS for 5\% damping, computed from the acceleration time histories obtained at the 3rd floor at points $\mathrm{A}$ and $\mathrm{D}$ in both $X$ and $Y$ directions are shown in Figs. 11 and 12 , respectively. A satisfactory agreement between the numerical results (means and medians) and the experimental measurements appeared in a clear way. Another point of interest was the discrepancy exhibited by the numerical outputs. It was interesting to notice that the highest discrepancy was achieved in the frequency range $10-20 \mathrm{~Hz}$, while the discrepancy for frequencies higher than $30 \mathrm{~Hz}$ was lower. A satisfactory agreement can be observed except in the case of point $\mathrm{D}$ in the $Y$ direction; in the $X$ direction, the experimental responses were underestimated in the frequency range $0-20 \mathrm{~Hz}$, while the zero period acceleration (ZPA) was well captured. In the $Y$ direction, the mean results showed an opposite trend. Nevertheless, the mean was not a robust tool, since it was largely influenced by outliers; the median was better suited for skewed distributions to derive a central tendency, since it was much more robust and sensible. Therefore, from these considerations, it could be assessed that similar trends were observed in both $X$ and $Y$ directions. Moreover, the ZPAs computed from the median results calculated by the participants at the 3rd floor were compared with the experimental values at points $A, B$, C and D. The comparison is shown in Fig. 13.

The maximum relative displacement between the 3rd floor and the bottom of the foundation were also analyzed. The benchmark outputs are shown in Table 5 . The results provided by the participants were generally lower than the measurements. This showed that the structural stiffness was overestimated by the numerical models. Nevertheless, it was noteworthy that the values of the relative displacements were rather low, leading the authors to weight the conclusions that could be drawn based on this type of data. From the overall observations that were made in this section, it could be assessed that the numerical models were well calibrated.

\subsection{High-intensity seismic ground motion: overdesign level $-P G A=0.4 \mathrm{~g}$}

The predictive capability of the numerical models was assessed by asking the benchmark participants to carry out blind computations of an overdesign seismic run, of which the PGA was equal to $0.4 \mathrm{~g}$, i.e. twice the design PGA. Since it was shown in Section 3.2 that the numerical models could be considered suitably calibrated, the results presented hereafter were the indicator of the predictive capability. In Figs. 14 and 15, the FRS were computed for 5\% damping from the numerical outputs and were compared with the experimental measurements at points $\mathrm{A}$ and $\mathrm{D}$ in both $X$ and $Y$ directions. Considering mean and median numerical results obtained by the participants, one could notice their satisfactory agreement with the experimental measurements. In addition, a higher discrepancy appeared for point $\mathrm{D}$ than for point $\mathrm{A}$. This could be explained by the fact that point $\mathrm{D}$ was more sensitive to the seismic loading leading to a higher variability of the computed results. The peak frequencies were also well captured.
Specific attention has been paid to analyzing the capability of the numerical models to predict the value of the ZPAs measured at points $\mathrm{A}, \mathrm{B}, \mathrm{C}$ and $\mathrm{D}$ in both $X$ and $Y$ directions. The results are shown in Fig. 16 in terms of median ZPAs. Whatever the observation point and the direction considered, a similar trend appeared (experimental ZPAs overestimated by the numerical predictions), meaning that nonlinear numerical models were conservative when considering high-frequency range. Last, the maximal relative displacements (reference being the bottom of the foundation) computed at the 3rd floor were compared with the experimental measurements. The comparisons in both $X$ and $Y$ directions are shown in Table 6. A gap ranging from $20 \%$ to $25 \%$ could be observed, which is not drastically different from the one observed when dealing with the design run. A similar standard deviation ranging between $25 \%$ and $30 \%$ could be observed for the numerical maximum displacements at the design and overdesign runs (Tables 5 and 6). It was also interesting to notice that, in Fig. 15a, the first peak of the floor response spectrum computed from experimental measurements was not in accordance with the one computed from the numerical results. The experimental peak was shifted toward low frequencies. In other terms, the numerical models did not succeed in capturing the stiffness loss that occurred in the $X$ direction. On the contrary, a better agreement was reached in the $Y$ direction; the numerical frequency peaks were close to the ones measured experimentally. This difference between both directions could be explained by the degradation mechanism observed on the RC specimen during the seismic test sequence [16].

\section{Lessons learned from the International Benchmark}

In this section, the main key points highlighted during the benchmark exercise or that were discussed with the benchmark participants are reported. The main findings herein reported have been shared with the benchmark participants during two workshops jointly organized by the CEA, EDF and partially endorsed by the OECD/NEA and IAEA at CEA center located in Saclay (France) in 2008 and 2010.

\subsection{Lessons learned from the blind dynamic computations}

Due to the blind computations carried out within the framework of the benchmark, one could assess the accuracy of assessment methods and analyze the reasons for such dispersion. The first point that could be discussed is the fact that, in the case of design loading, both conventional and best-estimate assessment methodologies led to similar results in terms of response spectra for 5\% damping (Figs. 5-8). In addition, the discrepancy was approximately the same for both sets of results. The position of the frequency peaks was well captured, which was not surprising since the specimen behaved mainly elastically for such a seismic loading level.

The second aspect to be mentioned concerns the choice of the numerical models. The complex geometry of the specimen (assembly of several RC shear walls with openings combined with floors, beams and columns), characterized by high asymmetry prevents, in most cases, for the modeling of RC walls, the adoption of simplified approaches as: (a) macroelement-based models in which 1D nonlinear springs connect rigid beams [19-21], (b) 1D beam-column finite elements [22-24] and (c) finite element models based upon 1D or macro-elements [25-27]. Most of the participants, in fact, used shell finite elements to model shear walls and slabs.

Another point is related to the assessment methodologies used in the case of overdesign seismic loading. Most of the participants used nonlinear time history methods with a relatively low 


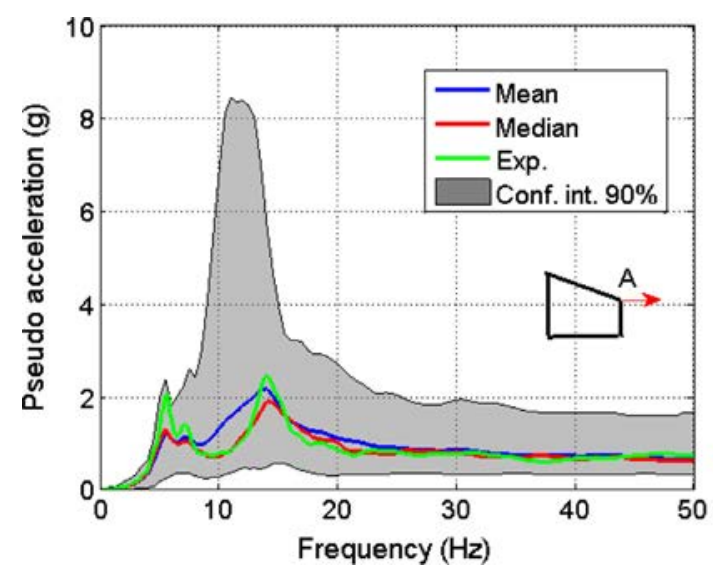

(a) $\mathrm{X}$ direction

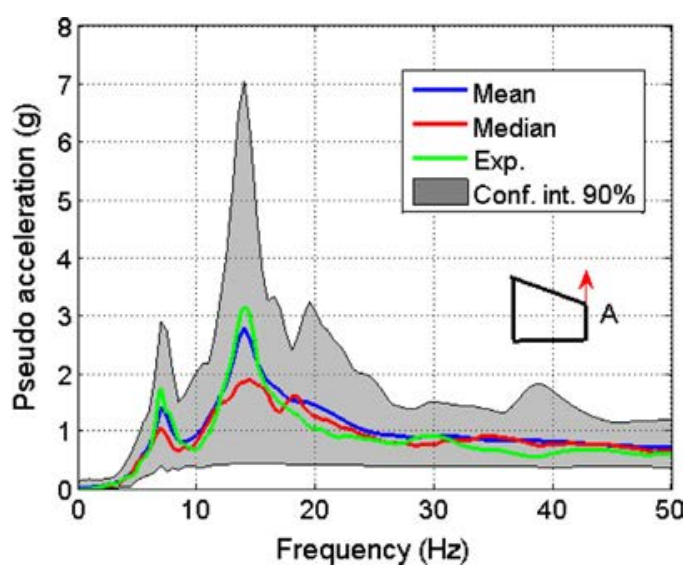

(b) Y direction

Fig. 11. Statistical description of the response spectra computed at point $A$ at the 3rd floor for $5 \%$ damping (design level $-\mathrm{PGA}=0.2 \mathrm{~g}$ ).

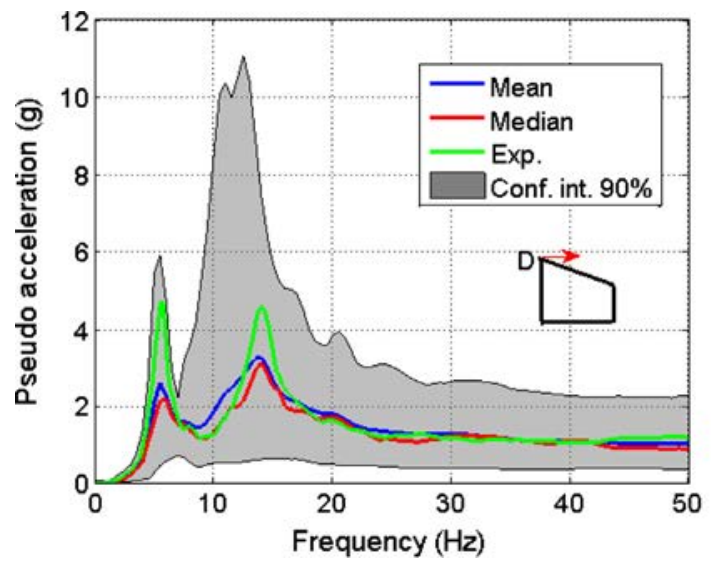

(a) $\mathrm{X}$ direction

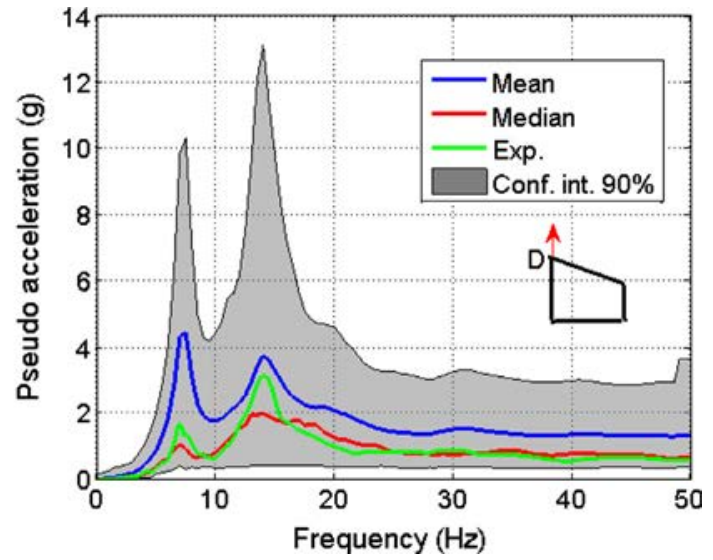

(b) $\mathrm{Y}$ direction

Fig. 12. Statistical description of the response spectra computed at point $D$ at the 3 rd floor for $5 \%$ damping (design level $-\mathrm{PGA}=0.2 \mathrm{~g}$ ).

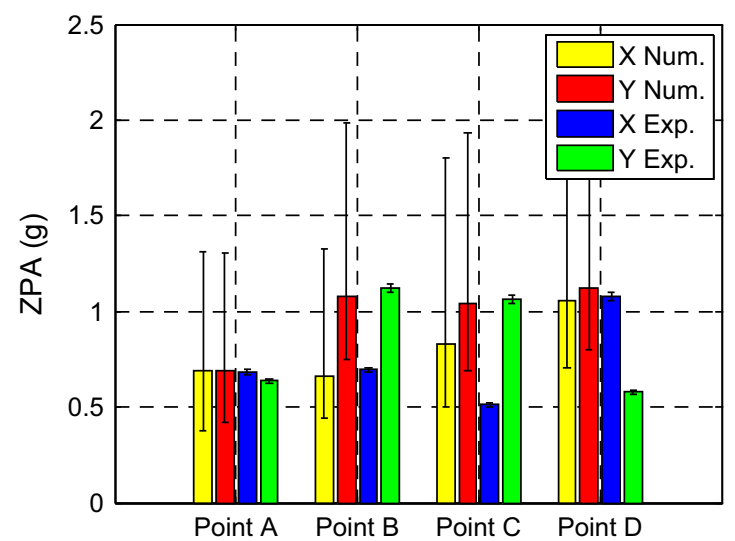

Fig. 13. Experimental versus numerical comparison of the ZPAs - median results design run.

damping ratio (mainly $2 \%$ ). Only a few participants used linear time history approaches or equivalent methods. It was interesting to notice that the modal spectral method was not used. This observation clearly showed that, when dealing with overdesign seismic loading, the current assessment practice adopted advanced nonlinear modeling technique instead of equivalent linear ones. This fact showed that the earthquake engineering community reached a good confidence level in nonlinear models when dealing with seismic loadings far from the design level.

The last key point concerned the robustness estimation of the specimen. The prediction of the seismic margins using two different failure criteria (global and local indicators) showed that the specimen could be considered robust. The numerical results coming from the benchmark exercise were corroborated by the experimental measurements carried out during the seismic testing campaign.

\subsection{Lessons learned from the post-test computations}

The post-test computations allowed the participants to check a posteriori that their numerical models were well calibrated and eventually to adjust them, especially in terms of initial modal properties. To carry out this check, both the design and overdesign loadings were considered. Among the adjustments made by the participants to reduce the gap between their numerical results and the experimental measurements, the introduction of the shaking table as part of the numerical model was critical, as the table did not behave as a perfectly rigid body. Indeed, this allowed the participants to fit the initial modal properties of the dynamic system; nevertheless, shaking table finite element idealization 
Table 5

Experimental/numerical comparisons of the maximum relative displacements at the $3^{\text {rd }}$ floor - design run.

\begin{tabular}{|c|c|c|c|c|c|c|c|}
\hline Direction & $\begin{array}{l}\text { Mean value } \\
(\mathrm{mm})\end{array}$ & $\begin{array}{l}\text { Median value } \\
(\mathrm{mm})\end{array}$ & $\begin{array}{l}\text { Maximal value } \\
(\mathrm{mm})\end{array}$ & $\begin{array}{l}\text { Minimal value } \\
(\mathrm{mm})\end{array}$ & $\begin{array}{l}\text { Coefficient of variation } \\
(\%)\end{array}$ & $\begin{array}{l}\text { Experimental measurement } \\
(\mathrm{mm})\end{array}$ & $\begin{array}{l}\text { Gap - (mean - exp.)/exp. } \\
(\%)\end{array}$ \\
\hline$X$ & 4.36 & 3.96 & 6.47 & 3.31 & 27 & 6.16 & -29 \\
\hline$Y$ & 4.29 & 4.09 & 5.86 & 3.10 & 26 & 5.34 & -19 \\
\hline
\end{tabular}

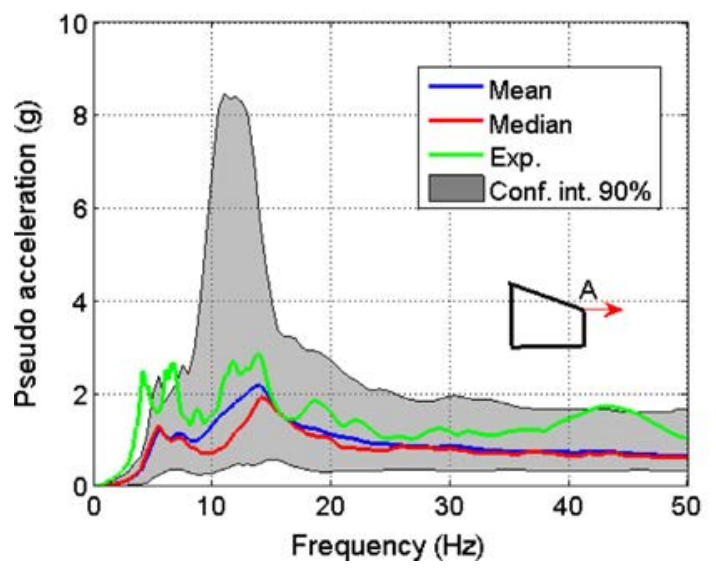

(a) $\mathrm{X}$ direction

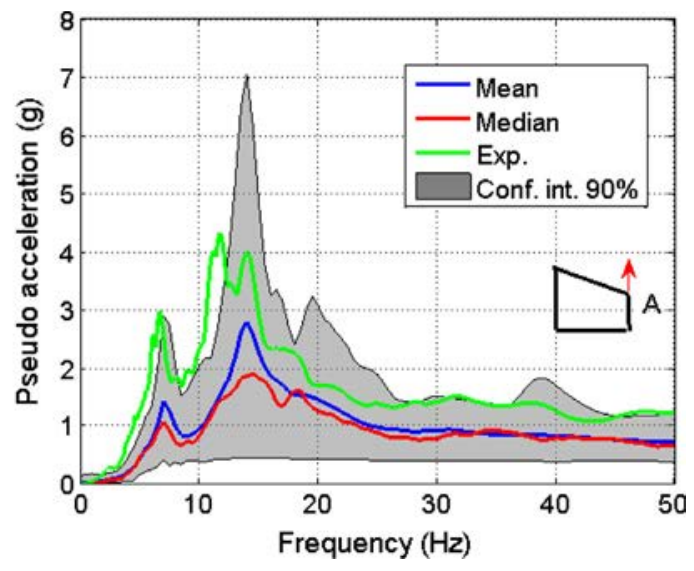

(b) $\mathrm{Y}$ direction

Fig. 14. Statistical description of the response spectra computed at point $A$ at the 3 rd floor for $5 \%$ damping (overdesign level $-\mathrm{PGA}=0.4 \mathrm{~g}$ ).

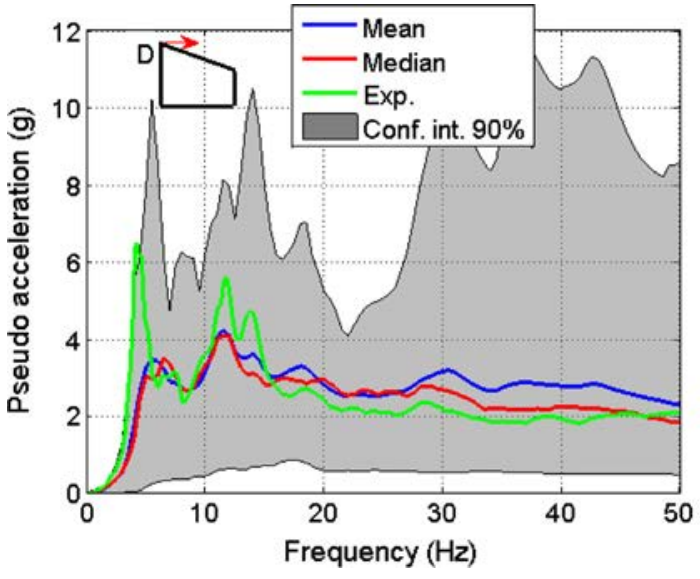

(a) $\mathrm{X}$ direction

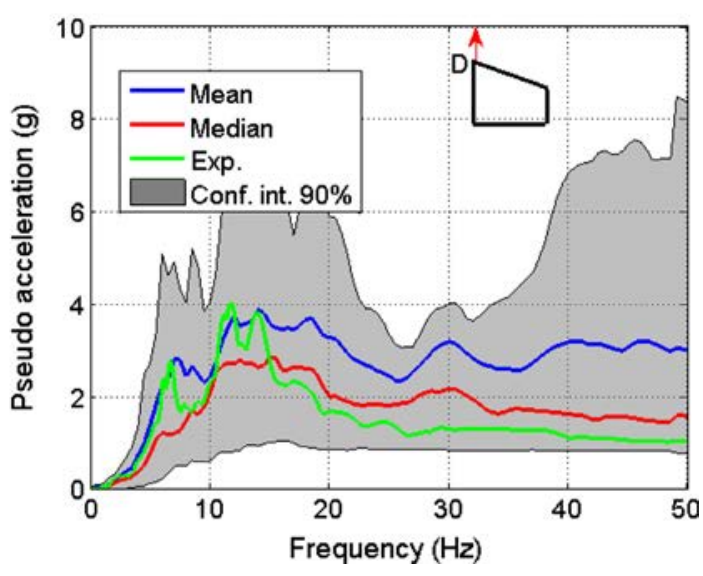

(b) $\mathrm{Y}$ direction

Fig. 15. Statistical description of the response spectra computed at point $\mathrm{D}$ at the $3 \mathrm{rd}$ floor for $5 \%$ damping (overdesign level $-\mathrm{PGA}=0.4 \mathrm{~g}$ ).

seemed to be out of range for most participants due to the difficulty of gathering needed data. In the case of design input ground motion, it is interesting to notice that the highest dispersion was observed for the frequency range between 10 and $20 \mathrm{~Hz}$ for both observation points $A$ and $D$ (Figs. 11 and 12). Looking at the results computed in both $X$ and $Y$ directions, it turned out that the median results were very close to the experimental ones. In addition, the benchmark exercise showed the ability of best-estimate methods to estimate the FRS in a satisfactory way.

In the case of the overdesign input ground motion, the discrepancy between the numerical and experimental results appeared higher compared to that obtained in the previous case. Since nonlinearities appeared during this loading stage, it was interesting to notice that the shift of the first peak frequency toward lowfrequencies in the $X$ direction was not captured as accurately as the one in the $Y$ direction (Figs. 14b and 15b). In addition, regarding the ZPAs, a similar trend was observed for all observation points (experimental ZPAs overestimated by the numerical predictions). We could also refer to the quite large dispersion between the results provided by participants, which could be explained by the variety of RC section nonlinear modeling assumptions and algorithms used in the calculations. We observed that displacements were underestimated while accelerations were overestimated in nonlinear range calculations provided by participants; this peculiarity could be attributed to the material energy dissipation that was not idealized by the numerical RC constitutive relations by participants.

The participants' results remain anonymous to ensure loyalty in processing the synthesis of the results. The large scattering of the outputs could be attributed to the fact that some participants did not give the expected dedication to the benchmark exercise, which resulted in poor contributions (far from the expected 


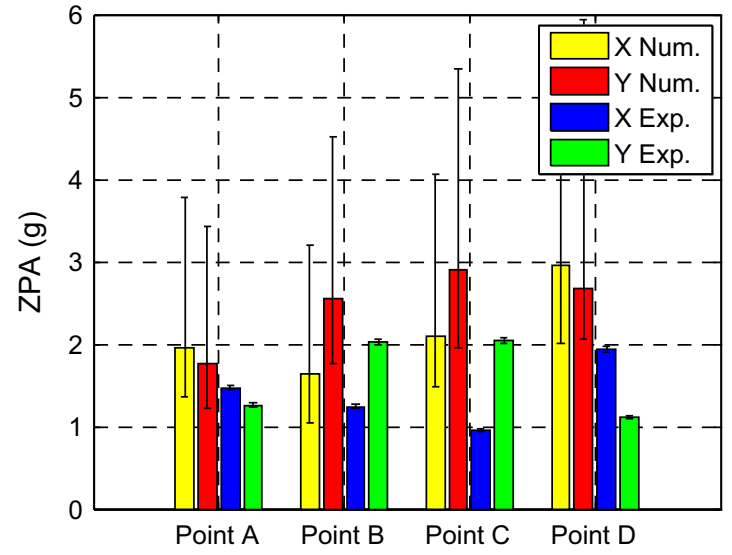

Fig. 16. Experimental versus numerical comparison of the ZPAs - median results overdesign run.

hand-calculated order of magnitude). As a consequence, it was necessary to eliminate some contributions to obtain a more suitable synthesis.

\subsection{Lessons learned from the two international workshops}

As parts of the SMART joint project, two workshops were organized at the CEA center located in Saclay in 2008 and 2010. The two workshops gathered most of the benchmark participants in order to create an area of sharing and discussion. The objectives of these workshops were to allow the participants to express their feeling and feedback about the benchmark and to discuss the synthesis of the benchmark exercise. Regarding the benchmark content, the high amount of numerical data required was pointed out by the participants. In particular, local quantities, such as strains or stresses, could have been omitted due to the difficulty to analyze them considering the large variety of the numerical models and modeling assumptions used. Moreover, a more in-depth point of discussion was related to the type of seismic input ground motions considered. The type of progressive seismic loadings based on synthetic signals artificially generated from the design spectra, having the same spectral distribution on the whole input motion sequence, was discussed; the progressive frequency shift of the specimen due to stiffness degradation from concrete damage could be responsible for a relative reduced dynamic solicitation for increasing seismic input motions. On the contrary, the cumulative effect of damage over the seismic sequence was also pointed out. A consensus on the fact that this loading was not fully consistent with a real seismic scenario mainly due to its progressive nature was reached; aftershock could be added to the seismic input motion sequence. This should be kept in mind for future benchmarks.

The last key area that could be improved in future benchmarks was related to the way the numerical models used by the participants and the modeling choices were characterized. This step could have been treated more deeply by asking close questions on key items to make the synthesis easier. Regarding the data provided to the participants, the concern of the control of the boundary conditions arose. Indeed, due to the complex kinematics of the shaking table during the loading stage, it could have been interesting to provide time history data at the level of the actuators (displacement, velocity and acceleration time histories) to better control the boundaries of the dynamic system. As a corollary of this latter point, the necessity to provide to the participants a shaking table finite element model able to ensure a good description of the tested dynamic system could be mentioned.

\section{Concluding remarks and outlooks}

This paper was dedicated to the presentation of the main findings from an International Benchmark carried out from 2008 to 2010 titled "Seismic design and best-estimate Methods Assessment for Reinforced concrete buildings subjected to Torsion and nonlinear effect" (SMART), organized by CEA and EDF and partially endorsed by OECD/NEA and the IAEA, based on experimental data resulting from a dedicated campaign carried out with an RC specimen on the Azalée shaking table. The objectives of the benchmark were (i) to share with the international community the current engineering practices to perform seismic assessments (in particular (1) to evaluate conventional design methods for structural dynamic responses and FRS calculations and (2) to compare bestestimate methods for structural dynamic responses and FRS evaluation) and (ii) to promote the use of probabilistic methodologies addressing random and epistemic uncertainties for vulnerability analyses. Thirty-four teams spread out over the world participated in the benchmark exercise. The teams came from nuclear companies, engineering offices, research centers and higher education institutions pointing out the common interest in the topics addressed in the benchmark.

Some key outputs from the benchmark have been presented in a synthetic way and discussed in this paper. Among the conclusions reached regarding the blind computations, the followings items can be pointed out. Both conventional and best-estimate methods led to satisfactory seismic assessments in terms of FRS and ZPAs under design input ground motion; numerical results (displacement and acceleration fields) matched well with recorded values on the SMART mock-up (for Run 6 at $0.2 \mathrm{~g}$ nominal ground acceleration). When dealing with overdesign input ground motions, the trend to use transient nonlinear methods to proceed to the structural assessment was clearly observed. The numerical results from the benchmark led to the conclusion that the specimen exhibited significant seismic margins, making it robust against extreme seismic loadings, as was confirmed by the experimental campaign carried out within the SMART project. It was interesting to notice that a group of six participants, who adopted common assumptions that could be regarded as representative of a reference practice, computed FRS in a good agreement with the recorded spectra for Run 6 (0.2 g); nevertheless, at Run 8 ( $0.4 \mathrm{~g})$, they obtained underestimated displacements and overestimated accelerations, presenting a significant discrepancy with respect to recorded values from experiments. This feature could be attributed to the difficulty to idealize the whole RC material dissipation with the proposed numerical constitutive models by participants. Regarding the post-test calculations, it was interesting to notice that the main adjustment made by the participants regarded including the shaking table interaction in their numerical models, which showed that it had a non-negligible effect on the numerical outputs. Even for overdesign loading, FRS were quite well described, showing a

Table 6

Experimental/numerical comparisons of the maximum relative displacements at the 3rd floor - overdesign run.

\begin{tabular}{|c|c|c|c|c|c|c|c|}
\hline Direction & $\begin{array}{l}\text { Mean value } \\
(\mathrm{mm})\end{array}$ & $\begin{array}{l}\text { Median value } \\
(\mathrm{mm})\end{array}$ & $\begin{array}{l}\text { Maximal value } \\
(\mathrm{mm})\end{array}$ & $\begin{array}{l}\text { Minimal value } \\
(\mathrm{mm})\end{array}$ & $\begin{array}{l}\text { Coefficient of variation } \\
\text { (\%) }\end{array}$ & $\begin{array}{l}\text { Experimental measurement } \\
(\mathrm{mm})\end{array}$ & $\begin{array}{l}\text { Gap - (mean - exp.)/exp. } \\
(\%)\end{array}$ \\
\hline$X$ & 11.94 & 10.94 & 14.33 & 7.20 & 25 & 15.08 & -20 \\
\hline$Y$ & 9.84 & 8.34 & 12.67 & 5.89 & 30 & 13.20 & -25 \\
\hline
\end{tabular}


certain maturity level of nonlinear approaches to perform the seismic assessment of such a complex specimen as the one tested within the framework of the SMART project.

In various countries, the conventional nuclear practices were based on the linear assumption behavior of the specimen to be assessed. This assumption was not justified since, even at the design level, small nonlinearities were exhibited during the SMART experimental campaign. The results from the benchmark exercise reported in this paper showed that numerous teams used almost straightforwardly nonlinear time history methodologies to estimate the dynamic response of the specimen for overdesign loadings. This showed that nonlinear approaches have, nowadays, reached a certain level of maturity, allowing their use for engineering issues when dealing either with existing or new nuclear building assessments. The trend identified within the framework of the SMART project was the use of best-estimate methods for seismic assessment either for design or overdesign seismic loadings in accordance with the recommendations made by the IAEA following the NUPEC benchmark [8]. Nevertheless, it seems that reliable computation of the floor response remains a major challenge of structural analysis. This challenge cannot be taken on without a proper modeling of nonlinear effects in RC constitutive behavior, even in the field of small non-linearity that occurs before the acceptance criteria are reached. In that sense, the SMART project helps to determine what should be completed to pursue our common quest of continuously improving the safety of nuclear plants.

The main perspectives of the work reported in this paper have been derived from fruitful and interesting discussions with all participants and contributors to the SMART joint project during the workshops. Three main perspectives and improvements can be pointed out in order to feed future benchmarks. First, a stage devoted to the characterization of nonlinear constitutive laws used in the numerical models to describe the energy dissipation during the seismic loading (in particular, overdesign ones) should be considered. Accurate and refined correlations between the modeling assumptions and the numerical outputs could be carried out. Second, particular attention should be paid to the choice of the seismic ground motions applied to the specimen. Indeed, despite the fact that progressive synthetic signals artificially generated from the design spectra have allowed for the estimation of the seismic margins, the seismic testing sequence led to the cumulative effect of damage that was not easy to take into account when assessing the structural behavior of the specimen. Finally, the boundary conditions appear to be a key point to be addressed in order to build a relevant and trustful numerical model of the specimen. This means that specific information at the actuator level should be provided to the benchmark participants in order to ensure a robust control of the boundary conditions. Besides this latter point, an alreadyvalidated shaking table finite element model could be provided to the participants, which would represent a great simplification when applying the seismic loading to the specimen.

\section{Acknowledgements}

The Authors would like to thank all the participants to the SMART 2008 project and the associated International Benchmark for the huge work carried out, namely: R. Crambuer, S. JusterLermitte, A. Saudy, A. Awad, M. Elgohary, F. Maillet, N. Brännberg, H. Ekman, G. Lebon, F. Ragueneau, R. Desmorat, C. Giry, J. Mazars, P. Pegon, A. Yakut, I. Kazaz, B. Thunell, J. Moore, Y. Mondet, A. Klein, U. Burmann, I.K. Choi, D. Hahm, A. Andonov, M. Kostov, K. Apostolov, D. Stefanov, K. Hibino, T. Takada, M.G. Mulas, M. Domaneschi, G.M. Atanasiu, S. Crijanovschi, JM. Vezin, A. Wahid, A. Courtois. CEA and EDF are also gratefully thanked for material and financial supports. The work reported in this paper has also been supported by the SEISM Institute (http://www.institut-seism.fr).

\section{References}

[1] Hasegawa T, Kumagai H, Irino K, Rots JG, Feenstra PH. Seismic analysis of RC shear wall. In: Proceedings fourteenth international conference on structural mechanics in reactor technology; 1997 [HKW/13].

[2] Kitada Y, Akino K, Terada K, Aoyama H, Miller A. Report on seismic shear wall international standard problem organized by OECD/NEA/CSNI. In: Proceedings fourteenth international conference on structural mechanics in reactor technology; 1997 [HKW/1].

[3] Minami T, Nishikawa T, Yoshimura M, Ono H. Study on the dynamic inelastic behavior of seismic shear walls of the reactor building. In: Proceedings fourteenth international conference on structural mechanics in reactor technology; 1997 [HKW/11].

[4] Ueda M, Seya H, Ohmiya Y, Taniguchi H, Kambayashi A. Nonlinear analysis of RC shear wall shaking table test. In: Proceedings fourteenth international conference on structural mechanics in reactor technology; 1997 [HKW/16].

[5] Ile N, Reynouard JM. Nonlinear analysis of reinforced concrete shear wall under earthquake loading. J Earthquake Eng 2000;4(2):183-213.

[6] Bisch Ph, Coin A. The CAMUS research programme. In: Proceedings of the 11th European conference on earthquake engineering, Paris, France, Balkema, Rotterdam, 4-8th September 1998.

[7] Queval JC, Combescure D, Sollogoub P, Coin A, Mazars J. CAMUS experimental program. In - plane tests of $1 / 3$ rd scaled $R / C$ bearing walls. In: Proceedings of the 11th European conference on earthquake engineering, Paris, France, Balkema, Rotterdam, 4-8th September 1998.

[8] Labbé P, Altinyollar A. Conclusions of an IAEA-JRC research project on the safety significance of near-field seismic motions. Nucl Eng Des 2011;241 (5):1842-56

[9] Panagiotou M, Restrepo JI, Conte JP. Shake-table test of a full-scale 7-story building slice. Phase I: rectangular wall. J Struct Eng 2011;137(6):691-704.

[10] Waugh JD, Sritharan S. Lessons learned from seismic analysis of a seven-story concrete test building. J Earthquake Eng 2010;14(3):448-69.

[11] Martinelli P, Filippou F. Simulation of the shaking table test of a seven-story shear wall building. Earthq Eng Struct Dynam 2009;38(5):587-607.

[12] Grange S, Kotronis P, Mazars J. Numerical modelling of the seismic behaviour of a 7-story building: NEES benchmark. Mater Struct 2009:42(10):1433-42.

[13] Kelly T. A blind prediction test of nonlinear analysis procedures for reinforced concrete shear walls. NZSEE Bullet 2007;40(3):142-59.

[14] Simos N, Hofmayer C-H. Experimental studies of reinforced concrete structures under multi-directional earthquakes and design implications, July 2013 [NUREG/CR-7119].

[15] Juster-Lermitte S, Chaudat Th, Courtois A. SMART 2008 project experimental tests of a reinforced concrete building subjected to torsion. In: Proceedings 20th international conference on structural mechanics in reactor technology; 2009 [Paper Div.V-1700].

[16] Richard B, Martinelli P, Voldoire F, Corus M, Chaudat T, Abouri S, Bonfils N SMART 2008: shaking table tests on an asymmetrical reinforced concrete structure and seismic margins assessment. Eng Struct 2015. http://dx.doi.org/ 10.1016/i.engstruct.2015.09.036.

[17] Frau A, Richard B. Damping identification in shaking table tests. In: Proceedings of the technical innovation in nuclear civil engineering international conference (TINCE 2013), Cachan, France; 2013.

[18] Heidebrecht AC, Naumoski ND. Development and application of a displacement-based design approach for moment-resisting frame structures. In: Fajfar P, Krawinkler H, editors. Seismic design methodologies for the next generation of codes. Rotterdam: AA Balkema; 1997. p. 217-28.

[19] Ghobarah A, Youssef M. Modelling of reinforced concrete structural walls. Eng Struct 1999;21:912-23.

[20] Orakcal K, Wallace JW, Conte JP. Flexural modeling of reinforced concrete walls - model attributes. ACI Struct J 2004:101(5):688-98.

[21] Jalali A, Dashti F. Nonlinear behavior of reinforced concrete shear walls using macroscopic and microscopic models. Eng Struct 2010;32:2959-68.

[22] Belmouden Y, Lestuzzi P. Analytical model for predicting nonlinear reversed cyclic behaviour of reinforced concrete structural walls. Eng Struct 2007;29:1263-76

[23] Ceresa P, Petrini L, Pinho R. Flexure-shear fiber beam-column elements for modeling frame structures under seismic loading - state of the art. J Earthc Eng 2007;11(S1):46-88.

[24] Thomson ED, Perdomo ME, Picón R, Marante ME, Flórez-López J. Simplified model for damage in squat RC shear walls. Eng Struct 2009;31(10):2215-23.

[25] Liao FY, Han LH, Tao Z. Performance of reinforced concrete shear walls with steel reinforced concrete boundary columns. Eng Struct 2012;44:186-209.

[26] Kazaz I, Gülkan P, Yakut A. Performance limits for structural walls: an analytical perspective. Eng Struct 2012;43:105-19.

[27] Martinelli L, Martinelli P, Mulas MG. Performance of fiber beam-column elements in the seismic analysis of a lightly reinforced shear wall. Eng Struct 2013;49:345-59. 